\title{
Conceptual changes in small-for-size graft and small-for-size syndrome in living donor liver transplantation
}

\author{
Toru Ikegami ${ }^{1}$, Jong Man Kim², Dong-Hwan Jung ${ }^{3}$, Yuji Soejima ${ }^{4}$, Dong-Sik Kim ${ }^{5}$, Jae-Won Joh ${ }^{2}$, \\ Sung-Gyu Lee ${ }^{3}$, Tomoharu Yoshizumi ${ }^{1}$, Masaki Mori ${ }^{1}$ \\ ${ }^{1}$ Department of Surgery and Science, Kyushu University, Fukuoka, Japan; \\ ${ }^{2}$ Department of Surgery, Samsung Medical Center, Sungkyunkwan University School of Medicine, Seoul, Korea; \\ ${ }^{3}$ Department of Liver Transplantation and Hepatobiliary and Pancreatic Surgery, Asan Medical Center, \\ Ulsan University School of Medicine, Seoul, Korea; \\ ${ }^{4}$ Department of Surgery, Shinshu University School of Medicine, Matsumoto, Japan; \\ ${ }^{5}$ Division of Hepatobiliary and Pancreatic Surgery and Liver Transplantation, Department of Surgery, \\ Korea University College of Medicine, Seoul, Korea
}

\begin{abstract}
Early series in living donor liver transplantation (LDLT) in adults demonstrated a lower safe limit of graft volume standard liver volume ratio $25 \%-45 \%$. A subsequent worldwide large LDLT series proposed a 0.8 graft recipient weight ratio (GRWR) to define small-for-size graft (SFSG) in adult LDLT. Thereafter, researchers identified innate and inevitable factors including changes in liver volume during imaging studies and graft shrinkage due to perfusion solution. Although the definition of small-for-size syndrome (SFSS) advocated in the 2000s was mainly based on prolonged cholestasis and ascites output, the term SFSS was inadequate to describe clinical manifestations possibly caused by multiple factors. Thus, the term "early allograft dysfunction (EAD), " characterized by total bilirubin $>10 \mathrm{mg} / \mathrm{dL}$ or coagulopathy with international normalized ratio $>1.6$ on day 7, has become prevalent to describe graft dysfunction including SFSS after LDLT. Although various efforts have been made to overcome EAD in LDLT, graft selection to maintain an expected GRWR $>0.8$ and full venous drainage, as well as inflow modulation using splenic artery ligation, have become standard in recent LDLT.
\end{abstract}

Keywords: Living donor liver transplantation; Small-for-size graft; Small-for-size-syndrome; Early allograft dysfunction

\section{INTRODUCTION}

Living donor liver transplantation (LDLT) was first introduced for pediatric patients in Brazil in 1989 [1], the positive outcomes of which resulted in the gradual recognition of LDLT as a treatment of choice for pediatric patients with end-stage liver diseases [2]. In 1993, Kawasaki et al. [3] reported in their pediatric LDLT series that a graft volume standard liver volume ratio (GV/SLV) of

Received December 23, 2019

Accepted December 29, 2019

Correspondence to: Toru Ikegami

Department of Surgery and Science, Kyushu University, Fukuoka, Japan

Tel: +81-92-642-5466, Fax: +81-92-642-5482

E-mail: tikesurg@surg2.med.kyushu-u.ac.jp
$46 \%$ was within the safe limit. They were the first to use the term "small-for-size (SFS)" graft to describe grafts with GV/SLV <1.0. In 1994, the same Shinshu group [4] performed the first LDLT in adults using a left lobe graft with a GV/SLV of $45 \%$ in a small adult female recipient. In 1996, a Hong Kong group [5] reported successful adult LDLT using a left lobe graft with $25 \%$ of the ideal liver size in a patient with acute liver failure, thus demonstrating that an SLV of $25 \%$ was within the limit for successful LDLT.

However, Emond et al. [6] reviewed pediatric LDLTs using lateral segment grafts $(n=23)$ and adult LDLT using left lobe grafts $(n=2)$, reporting delayed functional recoveries in five recipients receiving a SFS graft defined as $<50 \%$ of the expected total liver size and non-funclicenses/by-nc/4.0/) which permits unrestricted non-commercial use, distribution, and reproduction in any medium, provided the original work is properly cited. 


\section{HIGHLIGHTS}

- Small-for-size graft expected graft recipient weight ratio (GRWR) cutoff of 0.8 .

- Volume-related factors may significantly affect graft survival in living donor liver transplantation (LDLT).

- Early allograft dysfunction characterized by prolonged cholestasis and coagulopathy on day 7 after LDLT may fit the clinical presentations of post-LDLT graft dysfunction better than small-for-size syndrome.

- Graft selection to maintain an expected GRWR $>0.8$, and full venous drainage and inflow modulation using splenic artery ligation may become the standard.

tion as a case with $23 \%$ of the expected total liver size. They reported that an SFS graft $<50 \%$ of the expected total liver size showed characteristic pathological presentations including ischemia, cholestasis, and regeneration after LDLT. Under such circumstances, the Hong Kong group [7] in turn reported that right lobe grafts with the middle hepatic vein should be used in adult LDLT to prevent SFS-related graft dysfunction, demonstrating the safety of removing the extended right lobe in donors.

\section{DEFINING SFSG}

In 1997, the Kyoto group also showed negative outcomes of left lobe grafts with graft recipient weight ratio (GRWR) <1.0, especially in older donors [8] and revised their strategy in 2000 to use mainly right lobe grafts without the middle hepatic vein in adult LDLT with GRWR $\geq 0.8$ [9]. Recently, the group decreased the lower limit of graft weight to a GRWR of 0.7 for under extensive inflow modulation using splenectomy [10]. The Kyushu group initially started the LDT program with a lower limit of GV/SLV of $30 \%$ with successful outcomes in the initial series [11]. However, the initial 50 cases performed with this strategy resulted in prolonged cholestasis and ascites output in $20 \%$ of cases. Therefore, to decrease the incidence of graft dysfunction and maximize the success rate, the Kyushu group instead used more right lobe grafts, not less than
$35 \%$ of the lower limit of GV/SLV, corresponding to a GRWR of $0.7 \%$ under aggressive graft inflow modulation [12]. In 2001, the Tokyo group reported prolonged cholestasis and elongation of prothrombin time for GV/SLV $<40 \%$, resulting in poor graft survival $(80 \%)$; thus, a GV/SLV of $40 \%$ has been used as the lower limit for graft selection since [13]. A literature review showed that the major LDLT transplant centers in Eastern and Western countries apply a GRWR of 0.8 or GV/SLV of $40 \%$ of the expected graft size as the safe limit for successful LDLT without inflow modulation [14-18]. Currently, SFSG can be defined as a GRWR of 0.8 or GV/SLV of $40 \%$, although small-for-size syndrome (SFSS) after an LDLT graft could be attributed to multiple factors including not only graft size but also donor age, graft steatosis, recipient condition, and portal hypertension [19-23].

\section{DIFFERENCES IN EXPECTED AND ACTUAL GRAFT VOLUMES}

When debating the graft volume (GV), we should consider the differences between expected and actual GVs. Urata et al. [24] showed that the conversion ratio for liver weight $(\mathrm{g})$ and liver volume $\left(\mathrm{cm}^{3}\right)$ was not 1.0 and should instead be $1.12 \mathrm{~g} / \mathrm{mL}$, with a possible error of 12\%. In 2001, Marcos et al. [25] described differences between hepatic venous-oriented radiological anatomy and portal-oriented surgical anatomy regarding the boundaries between the right and left lobes, possibly resulting in volume errors of $100 \mathrm{~g}$ with a $1-\mathrm{cm}$ deviation in the cutting line. However, three-dimensional (3D) volumetry software with possible portal-oriented 3D reconstruction of LDLT grafts and portal demarcation line-oriented donor hepatectomy technique, which was recently reported by Suh et al. [15], might address this bias. Hiroshige et al. [26] performed an experimental study in small animals to evaluate the changes in preserved graft weights, reporting that procured grafts lost $4 \%$ of their weight in 15 minutes during preservation due to the high osmolarity of the preservation solution. Radtke et al. [27] evaluated changes in liver volume by infusing contrast medium during computed tomography 
(CT) scans, reporting enlargement by as much as $7 \%$ during the venous phase from the plain phase and reduction of as much as $11 \%$ during procurement. Because $3 \mathrm{D}-\mathrm{CT}$ volumetry is usually performed using the venous CT phase, the differences between expected and actual volumes could be $18 \%$.

Because of these innate errors between the expected and actual GV, Yoneyama et al. [28] established coefficient factors of 0.84 and 0.86 for the right and left lobe grafts, respectively, to determine the expected and actual GVs. They also reported no difference in actual and expected cirrhotic liver volume for a coefficient factor of 1.01, suggesting that a soft and normal liver graft with good elasticity might have larger differences in predicted and actual graft weight and volume. Kayashima et al. [29] found higher graft shrinkage (14\%) during preservation in LDLT grafts procured from younger donors compared to those from older donors $(4.4 \%)$. Thus, most surgical papers might be describing actual GV, as highlighting good graft function even with small graft size. However, strategic descriptions of the graft selection may refer to the expected volume; the actual GV may be $15 \%-20 \%$ smaller. A transplant surgeon might have a chance to have an LDLT graft with enough predicted GV with a largely reduced GV on a back-table. Thus, the definition of an SFS graft could be 0.8 for the "expected" GRWR or $40 \%$ for the expected GV/SLV rather than for the actual GRWR or GV/SLV.

\section{DEFINING SFSS}

Ben-Haim et al. [30] first used the term "small-for-size syndrome (SFSS)" to describe an LDLT graft with cholestasis and coagulopathy in disparity with normalization of transaminase levels together with graft blood flow, although no objective definitions were described. They mentioned that recipient factors could contribute to SFSS and that GRWR as low as $0.6 \%$ can be used without SFSS in patients within Child A level, whereas GRWR $\geq 0.85 \%$ was necessary to avoid SFSS in those with Child-Pugh class B or C. Soejima et al. [31] proposed the first objective definition of SFSS in 2003 as total bilirubin $>5 \mathrm{mg} / \mathrm{dL}$ and daily ascites output exceeding $1 \mathrm{~L}$ at 14 days after LDLT. They revised the definition in 2005 as prolonged functional cholestasis, with total bilirubin $>10 \mathrm{mg} / \mathrm{dL}$ and daily ascites production $>1 \mathrm{~L}$ at postoperative day 14 with a graft survival rate of $90 \%$ [12]. In contrast, Dahm et al. [32] defined SFSS as GRWR $<0.8$ and the presence of two of the following for 3 consecutive days during the first postoperative week: total bilirubin $>5 \mathrm{mg} / \mathrm{dL}$, international normalized ratio (INR) $>2$ and encephalopathy grade 3 or 4 , excluding technical, immunological and infectious factors. Their definition focused on primary non-function after deceased donor liver transplantation [33] with a prompt presentation of non-functional liver. It also had problems including the exclusion of GRWR $\geq 0.8$ and focusing only on the very early period after LDLT without prolonged cholestasis. Thereafter, Hill et al. [34] defined SFSS in 2009 as the presence of significant cholestasis with serum bilirubin $>10$ $\mathrm{mg} / \mathrm{dL}$ after postoperative day 7 , coagulopathy with an INR $>1.5$, and daily ascites output $>2 \mathrm{~L}$ in the absence of technical problems. They used grafts with an expected GRWR $\geq 0.8$ and compared graft outcomes between the cases with actual GRWR $\geq 0.8$ and those $<0.8$. They concluded that graft size was not the only determinant of outcome after LDLT and that inflow modification may help to prevent certain problems associated with LDLT. Since the early 2000s, LDLT centers have adopted their own institutional policies regarding the lower cutoff for graft selection as 0.8 for GRWR and $40 \%$ of GV/SLV; thus, there is significant selection bias in terms of $\mathrm{GV}$ in the reports since that time. In the 2010s, factors including prolonged cholestasis and coagulopathy, in addition to GV, become the focus in describing graft dysfunction in LDLT caused by multiple factors besides $\mathrm{GV}$.

\section{EARLY ALLOGRAFT DYSFUNCTION RATHER THAN SFSS}

In 2012, Ikegami et al. [35] advocated a conceptual shift from SFSS to primary graft dysfunction after LDLT. Their review of adult LDLT cases showed a 
high early graft mortality rate $(50 \%)$ in patients with functional cholestasis, with total bilirubin $>20 \mathrm{mg} / \mathrm{dL}$ after post-LDLT day 7 , with very high sensitivity and specificity. Huge ascites as a manifestation of graft dysfunction did not negatively impact graft survival. Although GV did not affect the occurrence of primary graft dysfunction, model for end-stage liver disease (MELD) score $>15$, the presence of portosystemic shunt, donor age $>45$ years, portal venous pressure $>$ $20 \mathrm{mmHg}$ at the end of surgery, and operative blood loss $>10 \mathrm{~L}$ were associated with primary graft dysfunction in LDLT. The proposed typical pathological findings of primary graft dysfunction including SFSS were ballooned hepatocytes with cholestasis in the pericentral venous zone forming a demarcation line with healthy hepatocytes in the periportal zone. Higher serum peak total bilirubin level in primary graft dysfunction was also associated with the shift in the ballooned hepatocyte borderline with cholestasis from the central venous to portal areas (Fig. 1A and B). Pathological findings in primary graft dysfunction can be distinguished from cholestatic lobular hepatitis $\mathrm{C}$ by pan-lobular hepatocyte ballooning (Fig. 1C) and acute rejection with mixed cellular infiltrations around the periportal area (Fig. 1D).

In the meantime, the concept of early allograft dysfunction (EAD) characterized by high early aminotransferase levels, persistent cholestasis, and coagulopathy in the first week after LT in the use of extended-criteria donors for deceased donor liver transplantation has been accepted in Western countries [36-38]. Olthoff et al. [39] proposed a definition of $\mathrm{EAD}$ in LDLT as the presence of jaundice with bilirubin $>10 \mathrm{mg} / \mathrm{dL}$ or coagulopathy with an INR $>1.6$ on day 7 without technical complications. The following A2ALL study [40] showed that EAD, with a five-fold risk of short-term graft loss, was associated with a left lobe graft, smaller graft weight, higher preoperative bilirubin, higher portal pressure, higher donor age, and higher donor body mass index. The reasons for graft size for $\mathrm{EAD}$ in this study might be attributed to nation-wide studies including LDLT centers with small case numbers. The Kyoto group [41] evaluated the impact of EAD criteria, reporting that 22 patients $(8.5 \%)$ satisfied both criteria. Graft survival was significantly decreased by the coexistence of both factors $(68.2 \%)$, compared to only bilirubin $>10 \mathrm{mg} / \mathrm{dL} \quad(24.3 \%)$, INR $>1.6$ $(37.5 \%)$, and neither $(11.9 \%)$; however, SFS grafts
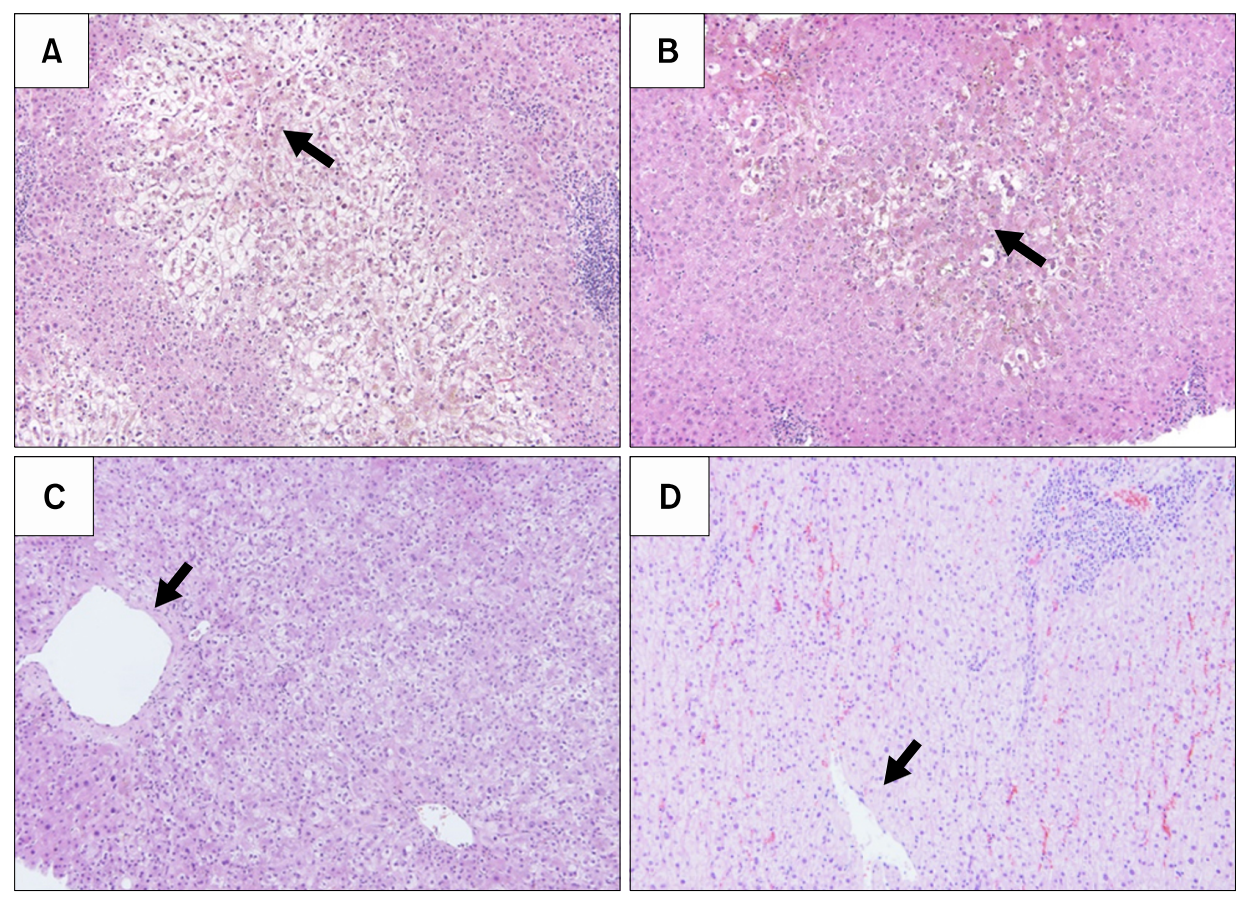

Fig. 1. Severe hepatocyte ballooning with cholestasis around the pericentral venous area (A) and the recovering phase (B), representing early allograft dysfunction (EAD) including small-for-size syndrome. The pathological findings with $\mathrm{EAD}$ can be distinguished from those of cholestatic lobular hepatitis $\mathrm{C}$ with panlobular hepatocyte ballooning (C) and acute rejection with mixed cellular infiltrations around the periportal area (D). Black arrows indicate central veins. 
Table 1. Definitions of early allograft dysfunction including small-for-size syndrome

\begin{tabular}{|c|c|c|}
\hline Study & & Definition \\
\hline Soejima et al. (2003) [31] & Small-for-size syndrome & $\begin{array}{l}\text { T.Bil }>5 \mathrm{mg} / \mathrm{dL} \text { at day } 14 \text { and ascites }>1 \mathrm{~L} \text { on day } 14 \text { or }>0.5 \mathrm{~L} \text { on day } \\
28\end{array}$ \\
\hline Soejima et al. (2006) [12] & Small-for-size syndrome & $\begin{array}{l}\text { T.Bil }>10 \mathrm{mg} / \mathrm{dL} \text { at day } 14 \text { and ascites }>1 \mathrm{~L} \text { on day } 14 \text { or }>0.5 \mathrm{~L} \text { on day } \\
28\end{array}$ \\
\hline Dahm et al. (2005) [32] & Small-for-size dysfunction & $\begin{array}{l}\text { GRWR }<0.8 \text { and the presence of two of the following for } 3 \text { consecutive days } \\
\text { during the first week: T.Bil }>100 \mu \mathrm{mol} / \mathrm{L}, \text { INR }>2 \text {, and encephalopathy } \\
\text { grade } 3 \text { or } 4\end{array}$ \\
\hline Hill et al. (2009) [34] & Small-for-size syndrome & $\begin{array}{l}\text { T.Bil }>10 \mathrm{mg} / \mathrm{dL} \text { (and continuing to increase) after day } 7, \text { INR }>1.5 \text {, and } \\
\text { ascites }>2 \mathrm{~L}\end{array}$ \\
\hline Ikegami et al. (2012) [35] & Primary graft dysfunction & T.Bil $>20 \mathrm{mg} / \mathrm{dL}$ after day 7 \\
\hline Olthoff et al. (2015) [39] & Early allograft dysfunction & Either T.Bil $>10 \mathrm{mg} / \mathrm{dL}$ or INR $>1.6$ on day 7 \\
\hline Okamura et al. (2018) [41] & Early allograft dysfunction & Both T.Bil $>10 \mathrm{mg} / \mathrm{dL}$ and INR $>1.6$ on day 7 \\
\hline
\end{tabular}

T.Bil, total bilirubin; GRWR, graft recipient weight ratio; INR, international normalized ratio.

with GRWR $<0.8$ did not negatively impact graft survival rates. The Kyoto EAD criteria in LDLT might be reasonable for graft mortality in LDLT; therefore, cholestasis and coagulopathy should be the primary manifestations related to graft mortality in EAD including SFSS. The various definitions for EAD including SFSS are listed in Table 1.

\section{HOW TO OVERCOME EAD AFTER LDLT}

The basic concept of EAD including SFSS is represented by the absence of technical complications, and inflow and outflow issues as previously described [42-44]. The major donor and recipient factors associated with EAD after DLLT include GRWR $<0.8$, donor age $>45$ years, MELD score $>20$, recipient with sarcopenia and unable to walk independently, posttransplant portal pressure $>15 \mathrm{mmHg}$, and post-LDLT complications including sepsis [17-20,30-35,42-44]. Because management of recipients with end-stage liver disease is difficult, donor and graft selection with inflow modulation to control portal pressure are the only options to overcome EAD.

Among inflow modulation methods, splenic artery ligation is widely recognized as the safest intervention with optimal outcomes [34,45-47]. The benefit of splenic artery ligation is attributed to increased hepatic arterial inflow due to obstruction of the splenic artery and decreased portal inflow via splenic outflow. The possible challenge in splenic artery ligation is the potential for bleeding and pancreas injury due to a deeply located splenic artery beneath the pancreas. The Kyushu group has performed simultaneous splenectomy during LDLT with the use of vessel sealing devices and endo-stapling devices to perform tie-less and blood-less splenectomy, with more potent decompression of portal inflow than that of splenic artery ligation [48-50]. The rationale for splenectomy is based on the fact that spleen is a major supplier of vasoconstrictive molecules, including endothelin, to the liver; thus, splenectomy results in hepatic vasodilatation [51,52]. Ikegami et al. [50] usually performed splenic artery ligation before splenectomy for easier and safer handling of enlarged spleens in end-stage liver disease. However, splenectomy is not globally recognized as a standard inflow modulation procedure in LDLT, except for the Kyushu and Kyoto groups, due to bleeding complications, portal and splenic venous thrombus, and post-splenectomy sepsis. Recently, the Asan group reported innovative splenic devascularization in LDLT, with sufficient portal decompression and fewer complications compared to those for splenectomy [53].

The creation of portosystemic shunts for portal decompression was first reported in the early to middle 2000s, with optimal outcomes in LDLT using extremely small grafts [54-56]. However, because of unstable 
portal inflow due to liver regeneration in LDLT and portal steal phenomena leading to graft mortality, no Japanese institute has recently performed this procedure [44]. We experienced a case requiring an extra-small graft with expected and actual GV/SLV of $36 \%$ and $23 \%$, respectively, from a 20-year-old donor into a patient with hepatocellular carcinoma, in which an end-to-side portocaval shut after splenectomy was created to modulate excessive portal inflow to the small graft [57]. The graft showed hepatofugal portal flow 4 days after surgery, followed by immediate re-laparotomy for shunt ligation, resulting in a good postoperative course. We should have recognized that this young and soft graft had an expected GV/SLV of $36 \%$ to accommodate sufficient portal flow and that the GV/SLV of $23 \%$ was a temporary presentation due to dehydration [26-29].

The generally recommended strategies for graft selection and inflow modulation might include the use of a modified right lobe graft with GRWR $>0.8$ and full venous drainage with splenic artery ligation. However, special techniques in LDLT could be performed in experienced LDLT centers for future development including the use of smaller grafts including the left lobe or posterior segment, the use of much larger grafts including dual grafts or extended right lobe graft, and technically demanding portal inflow modulations including tie-less splenectomy and creation of portosystemic shunts.

\section{CONCLUSION}

The historical changes over more than 25 years in LDLT include those from pediatric to adult patients, from a possible chance to generally accepted stable outcomes, and right lobe grafts with GRWR $>0.8$ becoming mainstream in LDLT, with worldwide expansion. We should recognize a SFS graft expected GRWR cutoff of 0.8 . Because volume-related factors may significantly affect graft survival in LDLT due to of institutional guidelines based on a GRWR $>0.8$, EAD characterized by prolonged cholestasis and coagulopathy on day 7 after LDLT may fit the clinical presentations of post-LDLT graft dys- function better than SFSS. Graft selection to maintain an expected GRWR $>0.8$, and full venous drainage and inflow modulation using splenic artery ligation may become the standard.

\section{ACKNOWLEDGMENTS}

\section{Conflict of Interest}

No potential conflict of interest relevant to this article was reported.

\section{Author Contributions}

Conceptualization: TI, JMK, MM. Project administration: DHJ, DSK, YS, JWJ, SGL. Visualization: TI, TY. Writing - original draft: TI. Writing - review \& editing: TI, JMK.

\section{Additional Contributions}

We appreciate great contributions with discussions for years regarding this main topic for Kyung-Suk Suh, Kwang-Woong Lee, and Nam-Joon Yi from Seoul National University, Gi-won Song and Ki-Hun Kim from Asan Medical Center, Soon-Il Kim, Myoung Soo Kim, and Dong Jin Joo from Yonsei University Health System, and Koo-Jeong Kang from Keimyung University Dongsan Medical Center.

\section{REFERENCES}

1. Raia S, Nery JR, Mies S. Liver transplantation from live donors. Lancet 1989;2:497.

2. Ozawa K, Uemoto S, Tanaka K, Kumada K, Yamaoka $\mathrm{Y}$, Kobayashi N, et al. An appraisal of pediatric liver transplantation from living relatives: initial clinical experiences in 20 pediatric liver transplantations from living relatives as donors. Ann Surg 1992;216:547-53.

3. Kawasaki S, Makuuchi M, Matsunami H, Hashikura Y, Ikegami T, Chisuwa $\mathrm{H}$, et al. Preoperative measurement of segmental liver volume of donors for living related liver transplantation. Hepatology 1993;18:1115-20.

4. Hashikura Y, Makuuchi M, Kawasaki S, Matsunami H, Ikegami T, Nakazawa Y, et al. Successful living-related partial liver transplantation to an adult patient. Lancet 1994;343:1233-4. 
5. Lo CM, Fan ST, Chan JK, Wei W, Lo RJ, Lai CL. Minimum graft volume for successful adult-to-adult living donor liver transplantation for fulminant hepatic failure. Transplantation 1996;62:696-8.

6. Emond JC, Renz JF, Ferrell LD, Rosenthal P, Lim RC, Roberts JP, et al. Functional analysis of grafts from living donors: implications for the treatment of older recipients. Ann Surg 1996;224:544-54.

7. Lo CM, Fan ST, Liu CL, Wei WI, Lo RJ, Lai CL, et al. Adult-to-adult living donor liver transplantation using extended right lobe grafts. Ann Surg 1997;226:261-70.

8. Kiuchi T, Kasahara M, Uryuhara K, Inomata Y, Uemoto $\mathrm{S}$, Asonuma $\mathrm{K}$, et al. Impact of graft size mismatching on graft prognosis in liver transplantation from living donors. Transplantation 1999;67:321-7.

9. Inomata $\mathrm{Y}$, Uemoto S, Asonuma K, Egawa H. Right lobe graft in living donor liver transplantation. Transplantation 2000;69:258-64.

10. Uemura T, Wada S, Kaido T, Mori A, Ogura Y, Yagi $\mathrm{S}$, et al. How far can we lower graft-to-recipient weight ratio for living donor liver transplantation under modulation of portal venous pressure? Surgery 2016;159:1623-30.

11. Nishizaki $T$, Ikegami $T$, Hiroshige $S$, Hashimoto $K$, Uchiyama H, Yoshizumi T, et al. Small graft for living donor liver transplantation. Ann Surg 2001;233:575-80.

12. Soejima Y, Taketomi A, Yoshizumi T, Uchiyama H, Harada N, Ijichi $\mathrm{H}$, et al. Feasibility of left lobe living donor liver transplantation between adults: an 8-year, single-center experience of 107 cases. Am J Transplant 2006;6(5 Pt 1):1004-11.

13. Sugawara $\mathrm{Y}$, Makuuchi M, Takayama $\mathrm{T}$, Imamura $\mathrm{H}$, Dowaki S, Mizuta K, et al. Small-for-size grafts in living-related liver transplantation. J Am Coll Surg 2001;192:510-3.

14. Hwang S, Lee SG, Lee YJ, Sung KB, Park KM, Kim $\mathrm{KH}$, et al. Lessons learned from 1,000 living donor liver transplantations in a single center: how to make living donations safe. Liver Transpl 2006;12:920-7.

15. Suh KS, Suh SW, Lee JM, Choi Y, Yi NJ, Lee KW. Recent advancements in and views on the donor operation in living donor liver transplantation: a single-center study of 886 patients over 13 years. Liver Transpl 2015; 21:329-38.

16. Chan SC, Lo CM, Ng KK, Fan ST. Alleviating the burden of small-for-size graft in right liver living donor liver transplantation through accumulation of experience. Am J Transplant 2010;10:859-67.
17. Goldaracena N, Sapisochin G, Spetzler V, Echeverri J, Kaths M, Cattral MS, et al. Live donor liver transplantation with older ( $\geq 50$ years) versus younger $(<50$ years) donors: does age matter? Ann Surg 2016;263: 979-85.

18. Botha JF, Langnas AN, Campos BD, Grant WJ, Freise $\mathrm{CE}$, Ascher NL, et al. Left lobe adult-to-adult living donor liver transplantation: small grafts and hemiportocaval shunts in the prevention of small-for-size syndrome. Liver Transpl 2010;16:649-57.

19. Ogura Y, Hori T, El Moghazy WM, Yoshizawa A, Oike $\mathrm{F}$, Mori A, et al. Portal pressure $<15 \mathrm{~mm} \mathrm{Hg}$ is a key for successful adult living donor liver transplantation utilizing smaller grafts than before. Liver Transpl 2010; $16: 718-28$.

20. Ikegami $T$, Yoshizumi $T$, Sakata K, Uchiyama $H$, Harimoto N, Harada N, et al. Left lobe living donor liver transplantation in adults: what is the safety limit? Liver Transpl 2016;22:1666-75.

21. Macshut M, Kaido T, Yao S, Yagi S, Ito T, Kamo N, et al. Older donor age is a risk factor for negative outcomes after adult living donor liver transplantation using smallfor-size grafts. Liver Transpl 2019;25:1524-32.

22. Kaido T, Ogawa K, Fujimoto Y, Ogura Y, Hata K, Ito $\mathrm{T}$, et al. Impact of sarcopenia on survival in patients undergoing living donor liver transplantation. Am J Transplant 2013;13:1549-56.

23. Kelly DM, Miller C. Understanding the splenic contribution to portal flow: the role of splenic artery ligation as inflow modification in living donor liver transplantation. Liver Transpl 2006;12:1186-8.

24. Urata K, Kawasaki S, Matsunami H, Hashikura Y, Ikegami $\mathrm{T}$, Ishizone $\mathrm{S}$, et al. Calculation of child and adult standard liver volume for liver transplantation. Hepatology 1995;21:1317-21.

25. Marcos A, Orloff M, Mieles L, Olzinski AT, Renz JF, Sitzmann JV. Functional venous anatomy for right-lobe grafting and techniques to optimize outflow. Liver Transpl 2001; 7:845-52.

26. Hiroshige S, Shimada M, Harada N, Shiotani S, Ninomiya $\mathrm{M}$, Minagawa R, et al. Accurate preoperative estimation of liver-graft volumetry using three-dimensional computed tomography. Transplantation 2003;75:1561-4.

27. Radtke A, Sotiropoulos GC, Nadalin S, Molmenti EP, Schroeder T, Lang H, et al. Preoperative volume prediction in adult living donor liver transplantation: how much can we rely on it? Am J Transplant 2007;7:672-9. 
28. Yoneyama T, Asonuma K, Okajima H, Lee KJ, Yamamoto $\mathrm{H}$, Takeichi $\mathrm{T}$, et al. Coefficient factor for graft weight estimation from preoperative computed tomography volumetry in living donor liver transplantation. Liver Transpl 2011; 17:369-72.

29. Kayashima H, Taketomi A, Yonemura Y, Ijichi H, Harada $\mathrm{N}$, Yoshizumi $\mathrm{T}$, et al. Accuracy of an age-adjusted formula in assessing the graft volume in living donor liver transplantation. Liver Transpl 2008;14:1366-71.

30. Ben-Haim M, Emre S, Fishbein TM, Sheiner PA, Bodian CA, Kim-Schluger L, et al. Critical graft size in adult-to-adult living donor liver transplantation: impact of the recipient's disease. Liver Transpl 2001;7:948-53.

31. Soejima Y, Shimada M, Suehiro T, Hiroshige S, Ninomiya $\mathrm{M}$, Shiotani S, et al. Outcome analysis in adult-to-adult living donor liver transplantation using the left lobe. Liver Transpl 2003;9:581-6.

32. Dahm F, Georgiev P, Clavien PA. Small-for-size syndrome after partial liver transplantation: definition, mechanisms of disease and clinical implications. Am J Transplant 2005;5:2605-10.

33. Kulik U, Lehner F, Klempnauer J, Borlak J. Primary non-function is frequently associated with fatty liver allografts and high mortality after re-transplantation. Liver Int 2017;37:1219-28.

34. Hill MJ, Hughes M, Jie T, Cohen M, Lake J, Payne WD, et al. Graft weight/recipient weight ratio: how well does it predict outcome after partial liver transplants? Liver Transpl 2009;15:1056-62.

35. Ikegami T, Shirabe K, Yoshizumi T, Aishima S, Taketomi YA, Soejima Y, et al. Primary graft dysfunction after living donor liver transplantation is characterized by delayed functional hyperbilirubinemia. Am J Transplant 2012;12:1886-97.

36. Hoyer DP, Paul A, Gallinat A, Molmenti EP, Reinhardt $\mathrm{R}$, Minor $\mathrm{T}$, et al. Donor information based prediction of early allograft dysfunction and outcome in liver transplantation. Liver Int 2015;35:156-63.

37. Lee DD, Singh A, Burns JM, Perry DK, Nguyen JH, Taner CB. Early allograft dysfunction in liver transplantation with donation after cardiac death donors results in inferior survival. Liver Transpl 2014;20:1447-53.

38. Wadei HM, Lee DD, Croome KP, Mai ML, Golan E, Brotman R, et al. Early allograft dysfunction after liver transplantation is associated with short- and long-term kidney function impairment. Am J Transplant 2016;16: 850-9.
39. Olthoff KM, Emond JC, Shearon TH, Everson G, Baker TB, Fisher RA, et al. Liver regeneration after living donor transplantation: adult-to-adult living donor liver transplantation cohort study. Liver Transpl 2015;21:79-88.

40. Pomposelli JJ, Goodrich NP, Emond JC, Humar A, Baker TB, Grant DR, et al. Patterns of early allograft dysfunction in adult live donor liver transplantation: the A2ALL experience. Transplantation 2016;100:1490-9.

41. Okamura Y, Yagi S, Sato T, Hata K, Ogawa E, Yoshizawa A, et al. Coexistence of bilirubin $\geq 10 \mathrm{mg} / \mathrm{dL}$ and prothrombin time-international normalized ratio $\geq 1.6$ on day 7: a strong predictor of early graft loss after living donor liver transplantation. Transplantation 2018;102:440-7.

42. Kiuchi T, Tanaka K, Ito T, Oike F, Ogura Y, Fujimoto $\mathrm{Y}$, et al. Small-for-size graft in living donor liver transplantation: how far should we go? Liver Transpl 2003; 9:S29-35.

43. Ikegami T, Shimada M, Imura S, Arakawa Y, Nii A, Morine Y, et al. Current concept of small-for-size grafts in living donor liver transplantation. Surg Today 2008; 38:971-82.

44. Yagi S, Uemoto S. Small-for-size syndrome in living donor liver transplantation. Hepatobiliary Pancreat Dis Int 2012;11:570-6.

45. Lo CM, Liu CL, Fan ST. Portal hyperperfusion injury as the cause of primary nonfunction in a small-for-size liver graft-successful treatment with splenic artery ligation. Liver Transpl 2003;9:626-8.

46. Cheng YF, Huang TL, Chen TY, Concejero A, Tsang LL, Wang CC, et al. Liver graft-to-recipient spleen size ratio as a novel predictor of portal hyperperfusion syndrome in living donor liver transplantation. Am J Transplant 2006;6:2994-9.

47. Humar A, Beissel J, Crotteau S, Cohen M, Lake J, Payne WD. Delayed splenic artery occlusion for treatment of established small-for-size syndrome after partial liver transplantation. Liver Transpl 2009;15:163-8.

48. Ikegami T, Shirabe K, Soejima Y, Yoshizumi T, Uchiyama $\mathrm{H}$, Yamashita Y, et al. Strategies for successful left-lobe living donor liver transplantation in 250 consecutive adult cases in a single center. J Am Coll Surg 2013;216:353-62.

49. Yoshizumi $\mathrm{T}$, Taketomi A, Soejima Y, Ikegami $\mathrm{T}$, Uchiyama $\mathrm{H}$, Kayashima $\mathrm{H}$, et al. The beneficial role of simultaneous splenectomy in living donor liver transplantation in patients with small-for-size graft. Transpl Int 2008;21:833-42.

50. Ikegami T, Toshima T, Takeishi K, Soejima Y, Kawanaka 
$\mathrm{H}$, Yoshizumi $\mathrm{T}$, et al. Bloodless splenectomy during liver transplantation for terminal liver diseases with portal hypertension. J Am Coll Surg 2009;208:e1-4.

51. Uehara H, Akahoshi T, Kawanaka H, Hashimoto N, Nagao Y, Tomikawa M, et al. Endothelin-1 derived from spleen-activated Rho-kinase pathway in rats with secondary biliary cirrhosis. Hepatol Res 2012;42:1039-47.

52. Kawanaka $\mathrm{H}$, Akahoshi $\mathrm{T}$, Kinjo N, Iguchi $\mathrm{T}$, Ninomiya M, Yamashita YI, et al. Effect of laparoscopic splenectomy on portal haemodynamics in patients with liver cirrhosis and portal hypertension. Br J Surg 2014;101:1585-93.

53. Moon DB, Lee SG, Hwang S, Ahn CS, Kim KH, Ha TY, et al. Splenic devascularization can replace splenectomy during adult living donor liver transplantation: a historical cohort study. Transpl Int 2019;32:535-45.

54. Boillot O, Delafosse B, Méchet I, Boucaud C, Pouyet M. Small-for-size partial liver graft in an adult recipient: a new transplant technique. Lancet 2002;359:406-7.

55. Troisi R, Ricciardi S, Smeets P, Petrovic M, Van Maele G, Colle I, et al. Effects of hemi-portocaval shunts for inflow modulation on the outcome of small-for-size grafts in living donor liver transplantation. Am J Transplant 2005;5:1397-404

56. Yamada T, Tanaka K, Uryuhara K, Ito K, Takada Y, Uemoto S. Selective hemi-portocaval shunt based on portal vein pressure for small-for-size graft in adult living donor liver transplantation. Am J Transplant 2008;8: 847-53.

57. Ikegami T, Soejima Y, Taketomi A, Sanefuji K, Kayashima H, Harada N, et al. Living donor liver transplantation with extra-small graft: inflow modulation using splenectomy and temporary portocaval shunt. Hepatogastroenterology 2008;55:670-2. 